\title{
Quaternary Ammonium Bases in the Adductor Muscle of Fan-mussel
}

\author{
Tetsuhito HaYashi* and Shoji KonOSU*
}

(Received September 7, 1976)

\begin{abstract}
The ethanolic extract of the adductor muscle of fan-mussel, Atrina pectinata, was fractionated on Dowex 50W-X12 column. Of 19 Dragendorff-positive substances detected, 10 quaternary ammonium bases were isolated and identified as atrinine, carnitine, $\beta$-alanine betaine, glycine betaine, choline, $\gamma$-butyrobetaine, trimethylamine oxide, stachydrine, homarine, and trigonelline by comparing $\mathrm{mp}$, IR, UV, MS, and behaviors in TLC with those of the authentic compounds.
\end{abstract}

It was reported in our previous papers ${ }^{1-3)}$ that the adductor muscle of fan-mussel, Atrina pectinata, contained various betaines such as glycine betaine, $\beta$-alanine betaine, carnitine, and atrinine. In the course of these studies some 15 other Dragendorff-positive substances came under our notice in the aqueous ethanolic extract of the muscle. Attempts were made, therefore, to isolate and identify as many compounds as possible to give more comprehensive account of the composition of the quaternary ammonium bases. Ten substances of them, atrinine, carnitine, $\beta$-alanine betaine, glycine betaine, choline, $\gamma$-butyrobetaine, trimethylamine oxide, stachydrine, homarine, and trigonelline, were identified as described below.

\section{Experimental}

Materials and preparation of extract Fan-mussels were collected off the coast of Atsumi-cho, Aichi Prefecture, in July, 1975. The adductor muscles removed were frozen with dry ice and brought back to the laboratory. Aqueous ethanolic extract was prepared from $330 \mathrm{~g}$ of the muscle as described before. ${ }^{3}$ )

Separation of quaternary ammonium bases The extract was passed successively through columns of Amberlite $\mathrm{CG}-400\left(\mathrm{OH}^{-}\right.$form, $\left.200-400 \mathrm{mesh}, 2 \times 20 \mathrm{~cm}\right)$ and Amberlite CG-50 ( $\mathrm{H}^{+}$form, $\left.200-400 \mathrm{mesh}, 2 \times 40 \mathrm{~cm}\right)$ and the columns were washed with water. The percolate combined with the washings was concentrated under reduced pressure. The concentrate was poured onto a column of Dowex $50 \mathrm{~W}-\mathrm{X} 12\left(\mathrm{H}^{+}\right.$form, $200-400 \mathrm{mesh}, 3 \times$ $90 \mathrm{~cm}$ ) and quaternary ammonium bases were eluted with $\mathrm{HCl}$ by increasing the concentration stepwise as shown in Fig. 1. The flow rate was $130 \mathrm{ml} / \mathrm{hr}$ and $100 \mathrm{ml}$ fractions were collected.

Thin layer and paper chromatography For monitoring the elution of quaternary am-

* Laboratory of Marine Biochemistry, Faculty of Agriculture, The University of Tokyo, Bunkyo-ku, Tokyo（林 哲仁・鸿策章二: 東京大学農学部水産化学研究室). 
monium bases from the column of Dowex 50W-X12 and for isolating and identifying the bases, thin layer chromatography (TLC) on cellulose (Avicel SF) was carried out. Preparative paper chromatography (PC) for isolation of the bases was also effected using Toyo Filter Paper No. 514. The solvent systems used in these experiments were A) $95 \%$ ethanol$28 \%$ ammonium hydroxide $(85: 15, \mathrm{v} / \mathrm{v}), \mathrm{B}) 1$-butanol-acetic acid-water $(4: 1: 2, \mathrm{v} / \mathrm{v})$, and C) 2-propanol-0.05 $\mathrm{N}$ ammonium hydroxide $(2: 1, \mathrm{v} / \mathrm{v})$. The bases were detected by spraying the Dragendorff reagent.

Reagents The following authentic compounds were used for comparison with the isolated ones. Glycine betaine hydrochloride, DL-carnitine hydrochloride (Wako Pure Chem. Ind., Ltd.), choline chloride (Katayama Chem. Ind.), trimethylamine oxide hydrochloride, and trigonelline (Tokyo Chem. Ind. Co., Ltd.) were commercial preparations. These compounds were recrystallized, if necessary, before use. $\beta$-Alanine betaine hydrochloride and $\gamma$-butyrobetaine hydrochloride were synthesized after UTSUNOMIYA ${ }^{4)}$ and ABE and KANEDA, ${ }^{5)}$ respectively. Homarine hydrochloride and stachydrine were gifts from Dr. T. Hirano of Tokyo University of Fisheries and Dr. T. Yasumoto of Tohoku University, respectively. Atrinine hydrochloride was a preparation isolated from the adductor muscle of fan-mussel in our previous study."

\section{Results}

The elution patterns of Dragendorff-positive substances from the Dowex 50W-X12 column as examined by TLC are given in Fig. 1. They show the occurrence of at least 19

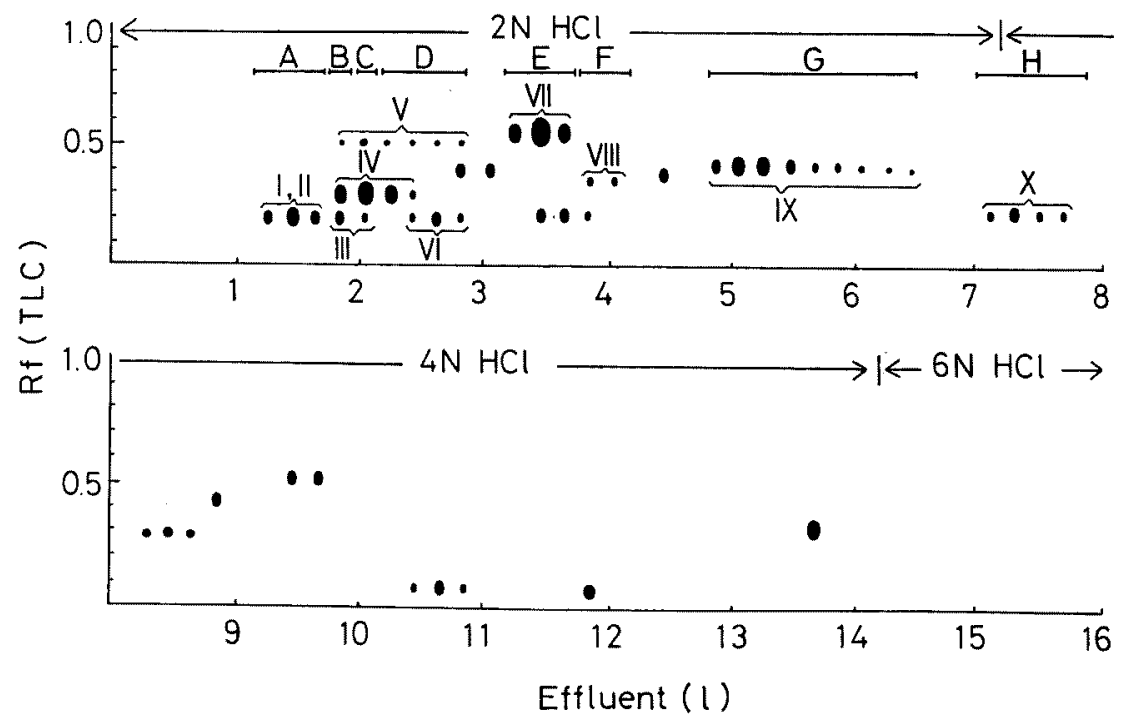

Fig. 1. Separation of Dragendorff-positive compounds in the adductor muscle of fan-mussel on Dowex $50 \mathrm{~W}-\mathrm{X} 12$ column $\left(\mathrm{H}^{+}\right.$form, $\left.200-400 \mathrm{mesh}, 3 \times 90 \mathrm{~cm}\right)$.

TLC: plate, cellulose (Avicel SF); solvent, $95 \% \mathrm{EtOH}-28 \% \mathrm{NH}_{4} \mathrm{OH}(85: 15, \mathrm{v} / \mathrm{v}$ ). 
tertiary amines and/or quaternary ammonium bases in the adductor muscle. The eluate was divided into Frs. A-H as indicated in the figure, and Compds. I-X in these fractions were isolated and identified as described below. The other 9 substances were not pursued further, because the sample sizes were too small to be analyzed.

Compds. I and II After removal of excess $\mathrm{HCl}$ by evaporation in vacuo, Fr. A was rechromatographed on Dowex 50W-X12 column ( $\mathrm{H}^{+}$form, 200-400 mesh, $1 \times 30 \mathrm{~cm}$ ) with $1 \mathrm{~N} \mathrm{HCl}$ as eluent at a flow rate of $10 \mathrm{ml} / \mathrm{hr}$. Compd. I was eluted between 120 and $140 \mathrm{~m} l$ and Compd. II between 145 and $160 \mathrm{~m} l$. On evaporation to dryness of the former fraction, crystals of Compd. I were obtained. Recrystallization from ethanoldiethyl ether gave $70 \mathrm{mg}$ of needles; $\mathrm{mp} 150.5^{\circ} \mathrm{C}$ (atrinine hydrochloride, $149-151^{\circ} \mathrm{C}^{\prime \prime}$ ). Rf values in TLC with Solvents A (0.26), B (0.36), and C (0.45) as well as IR were identical with those of authentic atrinine hydrochloride.

As Compd. II in the latter fraction was found to be still impure, it was subjected to preparative PC with Solvent A. The resulting band of Rf 0.26 was extracted with water. After addition of a small amount of $1 \mathrm{~N} \mathrm{HCl}$, the aqueous solution was evaporated to give $6 \mathrm{mg}$ of crystalline substance; $\mathrm{mp} 138^{\circ} \mathrm{C}$ (dec.) (L-carnitine hydrochloride, $142^{\circ} \mathrm{C}$, dec. $\left.{ }^{6}\right)$ ). IR and $R f$ values in TLC with Solvents A $(0.21), \mathrm{B}(0.25)$, and $\mathrm{C}(0.43)$ were coincident with those of authentic DL-carnitine hydrochloride.

Compd. III Evaporation residue of Fr. B was dissolved in a small amount of water and applied to a column of Dowex $50 \mathrm{~W}-\mathrm{X} 12\left(\mathrm{H}^{+}\right.$form, $\left.200-400 \mathrm{mesh}, 1 \times 105 \mathrm{~cm}\right)$. Then $0.7 \mathrm{~N} \mathrm{HCl}$ was allowed to flow through the column at a rate of $30 \mathrm{ml} / \mathrm{hr}$. Compd. III recovered between 730 and $750 \mathrm{~m} l$ was crystallized from ethanol-diethyl ether to give 38 $\mathrm{mg}$ of thin plates; $\mathrm{mp} 198^{\circ} \mathrm{C}$ ( $\beta$-alanine betaine hydrochloride, $\left.197-198^{\circ} \mathrm{C}^{2}\right)$. Both isolated substance and synthetic $\beta$-alanine betaine hydrochloride gave identical $\mathrm{IR}$ and $\mathrm{Rf}$ values in TLC with Solvents A (0.21), B (0.37), and C (0.39).

Compd. IV Evaporation of Fr. C gave crystals of Compd. IV. By recrystallizing thrice from aqueous ethanol, $72 \mathrm{mg}$ of prisms was obtained; $\mathrm{mp} 234^{\circ} \mathrm{C}$ (glycine betaine hydrochloride, $\left.236-238^{\circ} \mathrm{C}^{7}\right)$. IR and $\mathrm{Rf}$ values in TLC with Solvents $\mathrm{A}(0.29)$, B (0.36), and $C(0.49)$ were identical with those of authentic glycine betaine hydrochloride.

Compds. V and VI Evaporation residue of Fr. D was dissolved in a small amount of water and loaded onto a column packed with Whatman Cellulose Powder $(2 \times 45 \mathrm{~cm})$. The bases were eluted with a mixture of $95 \%$ ethanol and $28 \%$ ammonium hydroxide $(85$ : $15, \mathrm{v} / \mathrm{v}$ ) at a flow rate of $20 \mathrm{~m} l / \mathrm{hr}$. Compd. V appeared between 420 and $560 \mathrm{~m} l$ and Compd. VI which was contaminated with Compd. IV emerged between 740 and $1,000 \mathrm{~m} l$. The former fraction was concentrated to dryness and the residue dissolved in a small amount of $1 \mathrm{~N} \mathrm{HCl}$. Evaporation of the acidic solution yielded $1.2 \mathrm{mg}$ of light-brown solid. It gave a dark-brown spot in TLC with the Dragendorff reagent and showed a peak at $\mathrm{m} / \mathrm{e} 139$ in mass spectral analysis. These results strongly suggested that Compd. $\mathrm{V}$ is 
choline. Rf values in TLC with Solvents A (0.50) and B (0.39) and the color of spot were in agreement with those of authentic choline chloride.

The latter fraction containing largely Compd. VI was evaporated to dryness and the residue was dissolved in a small amount of water. The aqueous solution was applied to a column of Dowex $50 \mathrm{~W}-\mathrm{X} 12\left(\mathrm{H}^{+}\right.$form, $\left.200-400 \mathrm{mesh}, 1 \times 30 \mathrm{~cm}\right)$ and $1 \mathrm{~N} \mathrm{HCl}$ was allowed to flow through it at a rate of $15 \mathrm{ml} / \mathrm{hr}$. The compound was recovered between 230 and $250 \mathrm{ml}$ and finally purified twice by preparative TLC with Solvents A and B. Four $\mathrm{mg}$ of light-brown solid obtained was proved pure by TLC. Peaks at $\mathrm{m} / \mathrm{e} 131\left(\mathrm{Me}_{2} \mathrm{NCH}_{2}\right.$ $\left.\mathrm{CH}_{2} \mathrm{CH}_{2} \mathrm{COOH}\right)$ and $86\left(\mathrm{CH}_{2}=\mathrm{CHCH}_{2} \mathrm{COOH}\right)$ in the mass spectrum strongly suggested that Compd. VI is $\gamma$-butyrobetaine. Behaviors of the isolated substance and synthetic $\gamma$ butyrobetaine hydrochloride in TLC were identical in three solvents, A (0.19), B (0.43), and $\mathrm{C}(0.38)$.

Compd. VII Fr. E was subjected to cellulose column chromatography as described for Fr. D. Compd. VII appearing between 100 and $160 \mathrm{~m} l$ was further purified by preparative TLC with Solvent A. It was converted to hydrochloride and recrystallized twice from methanol-acetone to give $43 \mathrm{mg}$ of orthorhombic crystals; $\mathrm{mp} 239^{\circ} \mathrm{C}$. Not only $\mathrm{Rf}$ values in TLC with Solvents A (0.57), B (0.46), and C (0.48) but also mp and IR were in agreement with those of authentic trimethylamine oxide hydrochloride.

Compd. VIII Fr. F was rechromatographed on Dowex 50W-X12 as mentioned for Fr. A. Compd. VIII recovered between 290 and $320 \mathrm{~m} l$ was purified twice by preparative PC using Solvents A and B. Crystalline substance obtained (4 mg) was slightly brown in color. Mass spectrum gave peaks at $\mathrm{m} / \mathrm{e} 84$ and 129, which were assignable to N-methylpyrrolidine and its carboxylated compound, respectively. IR of the isolated substance was slightly different from that of authentic stachydrine, probably due to the presence of a small amount of impurity, but both substances were indistinguishable in TLC with two different solvents, A (0.35) and B (0.38).

Compd. IX On evaporation of Fr. G, crystals of Compd. IX were obtained. Recrystallization from methanol-acetone yielded $10 \mathrm{mg}$ of needles; $\mathrm{mp} 166-168^{\circ} \mathrm{C}$ (dec.) (homarine hydrochloride, $170-175^{\circ} \mathrm{C}$, dec. $\left.{ }^{8}\right)$. IR, UV at $\mathrm{pH} 1.0$, and $\mathrm{Rf}$ values in TLC with Solvents A (0.43) and B (0.42) were identical with those of authentic homarine hydrochloride.

Compd. X The residue obtained by evaporation of Fr. $\mathrm{H}$ was treated with $75 \%$ ethanol to give $11 \mathrm{mg}$ of light-brown crystalline substance. Its IR was almost indistinguishable from that of authentic trigonelline hydrochloride. $\mathrm{UV}$ at $\mathrm{pH} 1.0$ and $\mathrm{Rf}$ values in TLC with Solvents A (0.22) and B (0.36) coincided well with those of the authentic compound.

\section{Discussion}

The occurrence of a variety of quaternary ammonium bases in a single species of 
marine invertebrates has been demonstrated so far by several workers: WeLSH and PROCK ${ }^{9}$ showed the presence of tetramethylammonium, homarine, trigonelline, $\gamma$-butyrobetaine and/or zoo-anemonin in some coelenterates; BEERS ${ }^{10)}$ studied the distribution of homarine, trigonelline, glycine betaine, carnitine, and $\gamma$-butyrobetaine in a series of animals, mainly crustaceans, echinoderms, and tunicates; ACKERMANN and LIST ${ }^{11)}$ found herzynine, ergothioneine, homarine, trigonelline, glycine betaine, and choline in the horseshoe crab, Limulus polyphemus. Recently, YASUMOTO et al. ${ }^{12,13)}$ have indicated that the ovary of shellfish, Callista brevishiphonata, contained various quaternary ammonium compounds such as choline, glycine betaine, $\gamma$-butyrobetaine, stachydrine, homarine, and homoserine betaine, together with $\delta$-valerobetaine and valine betaine, both of which have not been observed so far in the nature. However, there seems no previous report in which the composition of quaternary ammonium bases in the muscle was investigated thoroughly. Therefore, we conducted the present study and revealed the complex composition of the bases. Except atrinine, 9 compounds identified have been reported occasionally to occur in the muscles of marine invertebrates, but the present work may be the first in which the coexistence of such a number of the bases was proved in one and the same muscle specimen.

No quantitative work has been made in this study, but the yield of each component and the chromatogram given in Fig. 1 are indicative of that glycine betaine, trimethylamine oxide, atrinine, and $\beta$-alanine betaine, especially the former two, are the major quaternary ammonium bases in the muscle of fan-mussel and that they constitute an important part of the nitrogenous extractives.

\section{Acknowledgements}

The authors are indebted to Prof. R. HiRano of The University of Tokyo for his help in collecting the fan-mussels. Thanks are also due to Dr. T. HIRANo of Tokyo University of Fisheries for generous supply of synthetic homarine hydrochloride. Grateful acknowledgement is made to Dr. T. Yasumoto of Tohoku University for assistance in the mass spectral analysis and a gift of synthetic stachydrine.

\section{References}

1) S. Konosu, Y.-N. Chen, and K. Watanabe: This Bull., 36, 940-944 (1970).

2) S. Konosu and K. Watanabe: ibid., 39, 645-648 (1973).

3) S. Konosu and T. HAYASHI: ibid., 41, 743-746 (1975).

4) Y. UtsunomiYa: J. Pharm. Soc. Japan, 87, 1422-1424 (1967).

5) S. ABE and T. KanedA: This Bull., 39, 391-393 (1973).

6) E. Strack und H. Schwaneberg: $Z$. physiol. Chem., 245, 11-18 (1937).

7) H. E. Carter and D. B. Melville: J. Biol. Chem., 133, 109-116 (1940).

8) M. Guggenherm: Die biogenen Amine, S. Karger, Basel, 1951, p. 279. 
9) J. H. Welsh and P. B. Prock: Biol. Bull, 115, 551-561 (1958).

10) J. R. BeErs: Comp. Biochem. Physiol., 21, 11-21 (1967).

11) D. ACKermann und P. H. List: Z physiol. Chem., 313, 30-36 (1958).

12) T. Yasumoto and F. SANo: This Bull., 40, 1163-1167 (1974).

13) T. Yasumoto and N. ShImizu: ibid., 43, 201-206 (1977). 